\title{
Implementasi Pembelajaran Matematika Materi Perkalian Kelas V pada Metode Lattice di Madrasah Ibtidaiyah (MI) Ar-Rohmah Glagahwangi Sugihwaras Bojonegoro
}

\author{
1Firda Zakiyatur Rofi'ah, ${ }^{2 *}$ Zulfatul Azizah \\ 1,2Universitas Nahdlatul Ulama Sunan Giri Bojonegoro \\ *firdazakiyautrrofiah@ymail.com
}

\begin{abstract}
Abstrak
Pemilihan metode yang tepat merupakan hal yang penting dalam proses pembelajaran. Untuk itu mempelajari dan memahami setiap metode pembelajaran secara teliti menjadi kewajiban setiap guru. Metode lattice adalah metode perkalian yang menggunakan kisi untuk mengalikan dua angka yang multi digit. Metode ini bisa menjadi alternatif dalam pembelajaran perkalian. Penelitian ini menggunakan pendekatan penelitian deskriptif kualitatif dengan teknik pengumpulan data yang di gunakan adalah observasi, wawancara, dan dokumentasi. Dan teknik analisis data menggunakan Pengumpulan data, Reduksi data, display data, Verifikasi dan penegasan kesimpulan. Hasil dari penelitian ini menunjukkan bahwa dalam implementasi pembelajaran matematika materi perkalian kelas $\mathrm{V}$ pada metode lattice dilakukan melalui tiga tahapan yaitu: penanaman konsep dasar, pemahaman konsep, dan pembinaan keterampilan. Hambatan dalam pembelajaran yaitu: Kurangnya konsentrasi siswa dalam pembelajaran karena adanya siswa yang sering usil dan gaduh, Kurangnya siswa dalam menghafalkan perkalian. Serta solusinya yaitu guru memberikan pembiasaan kepada siswa dalam setiap pembelajaran matematika siswa harus menghafal perkalian satu persatu, agar siswa cepat dalam menghafal perkalian.
\end{abstract}

Kata kunci: pembelajaran matematika, perkalian, metode Lattice.

\begin{abstract}
The selection of the right method is important in the learning process. For this reason, studying and understanding each method of learning carefully is the duty of every teacher. The lattice method is a multiplication method that uses a grid to multiply two multi-digit numbers. Lattice method is one alternative that can be used by teachers in multiplication learning. This study uses a descriptive qualitative research approach with data collection techniques used are observation, interviews, and documentation. The data analysis techniques using data collection, data reduction, data display, verification and confirmation of conclusions. The results of this study indicate that in the implementation of learning mathematics multiplication material class $v$ on the lattice method is carried out through three stages: planting basic concepts, understanding concepts, and developing skills. Barriers to learning are: Lack of student concentration in learning due to students who are often nosy and rowdy, Lack of students in memorizing multiplication. As well as the solution, namely: The teacher gives habituation to students in each mathematics learning students must memorize multiplication one by one, so students are quick in memorizing multiplication.
\end{abstract}

Keywords: Mathematics learning, multiplication, Lattice method

https://doi.org/. 


\section{PENDAHULUAN}

Pendidikan memegang peranan penting dalam mempersiapkan sumber daya manusia yang berkualitas. Oleh karena itu pendidikan hendaknya dikelola dengan baik. Hal tersebut bisa tercapai bila siswa dapat menyelesaikan pendidikan tepat pada waktunya dengan hasil belajar yang baik. Pendidikan erat kaitannya dengan pembelajaran. Definisi pembelajaran yaitu, segala upaya yang dilakukan oleh guru (pendidik) agar terjadi proses belajar pada diri siswa. Pada pembelajaran ada kegiatan memilih, menetapkan dan mengembangkan metode untuk mencapai hasil pembelajaran yang diinginkan. Pembelajaran akan efektif jika penggunaan metode sesuai dengan materi dan tujuan pembelajaran.

Metode pembelajaran merupakan pondasi awal untuk mencapai suatu tujuan dan asas pembelajaran. Metode tepat yang diterapkan dalam pembelajaran mampu mengatasi permasalahan yang dialami peserta didik. Namun jika metode yang dipakai tidak tepat maka hasil belajar pun tidak baik. Metode adalah suatu cara yang dipergunakan untuk mencapai tujuan yang telah di tetapkan.

Metode Lattice adalah metode perkalian yang menggunakan kisi untuk mengalikan dua angka yang multi digit. Metode Lattice merupakan salah satu alternatif yang dapat digunakan guru dalam pembelajaran perkalian. Metode ini dilakukan dengan proses yang lebih rapi dibandingkan dengan melakukan cara konvensional (bersusun). Pada cara konvensional, perhitungan perkalian dilakukan dengan perkalian dan penambahan yang silih berganti dengan bilangan asli. Kemudian, pada metode Lattice perhitungan perkalian dilakukan dengan menggunakan sebuah grid yang setiap selnya dibagi dua secara diagonal. Banyaknya sel disesuaikan dengan banyaknya digit bilangan yang dikalikan. Penggunaan metode lattice dalam perkalian mampu mengurangi kesalahan hitung yang sering dialami peserta didik.

Mengingat pentingnya kemampuan berhitung yang harus dikuasai oleh siswa MI, maka guru di MI Ar-Rohmah Glagahwangi mulai menerapkan metode yang inovatif dan interaktif untuk mengatasi masalah yang dialami oleh siswa dalam pembelajaran matematika. Kebanyakan siswa merasa kurang memahami materi jika hanya menggunakan metode ceramah dan tanya jawab, oleh sebab itu diperlukan metode yang lebih intensif untuk membantu siswa mencapai kemampuan berhitung yang lebih tinggi. Adapun metode yang dianggap solutif dalam hal ini adalah metode Lattice

Madrasah Ibtidaiyah Ar-Rohmah Glagahwangi Sugihwaras Bojonegoro merupakan salah satu madrasah yang menerapkan metode Lattice dalam pembelajaran matematika materi perkalian. Jika umumnya sekolah menggunakan berhitung perkalian dengan bersusun panjang atau konvensional, maka di Madrasah Ibtidaiyah Ar Rohmah Glagahwangi Sugihwaras Bojonegoro ini menggunakan metode Lattice. Hal ini bertujuan agar siswa mudah memahami perhitungan perkalian dengan baik dan benar.

Pendapat tersebut sesuai dengan hasil penelitian yang dilakukan oleh Solikin dkk (2019:51) menyimpulkan bahwa penggunaan metode lattice menunjukan para peserta didik sangat tertarik dengan metode yang baru mereka kenal. Mereka mampu menyelesaikan secara mandiri soal operasi perkalian setelah melalui empat treatment yang telah diberikan. Pada akhir treatment ratarata yang dicapai peserta didik ialah 84,30 dengan presentase ketuntasan mencapai 96,56\% dan kemampuan berhitungnya mengalami peningkatan 0.81 (kategori tinggi).

Berdasarkan uraian latar belakang diatas, maka peneliti tertarik untuk melakukan penelitian yang berjudul "Implementasi Pembelajaran Matematika Materi Perkalian Kelas V pada Metode Lattice di Madrasah Ibtidaiyah (Mi) Ar-Rohmah Glagahwangi Sugihwaras Bojonegoro" 
Penelitian ini memiliki tujuan antara lain: mengetahui implementasi pembelajaran matematika materi perkalian kelas V pada metode lattice di MI Ar-Rohmah Glagahwangi Sugihwaras Bojonegoro. Selain itu, penelitian ini digunakan untuk mengetahui hambatan dan solusi dalam implementasi pembelajaran matematika materi perkalian kelas $\mathrm{V}$ pada metode lattice di MI Ar-Rohmah Glagahwangi Sugihwaras Bojonegoro.

\section{METODE PENELITIAN}

Adapun pendekatan yang digunakan dalam penelitian lapangan ini adalah pendekatan kualitatif. Jenis penelitian ini menggunakan jenis penelitian deskriptif. Adapun alasan peneliti menggunakan penelitian Deskriptif Kualitatif adalah karena dalam penelitian ini data yang dihasilkan berupa data deskriptif yang diperoleh dari datadata berupa tulisan, kata-kata, dokumen yang berasal dari sumber atau informan yang di teliti dan dapat di percaya.

Lokasi penelitian terletak di MI Ar-Rohmah Glagahwangi Sugihwaras Bojonegoro. Peneliti memilih Madrasah ini karena di sinilah menggunakan metode perkalian yang berbeda dengan madrasah yang lain yaitu dengan menggunakan metode lattice. Sedangkan, di sekolah lain biasanya menggunakan metode perkalian bersusun panjang. Peneliti disini berperan sebagai peneliti non partisipan atau pengamat yang mengamati informan dan sumber data secara langsung.

Sumber data dalam penelitian ini meliputi dua jenis data, yaitu: sumber data utama (primer) dan sumber data tambahan (sekunder). Pertama, Data primer yaitu data yang diambil peneliti melalui observasi dan wawancara. Sumber data ini meliputi wawancara terhadap: Kepala Sekolah MI Ar-Rohmah Glagahwangi Sugihwaras, guru kelas V MI ArRohmah Glagahwangi Sugihwaras, siswa kelas V MI Ar-Rohmah Glagahwangi Sugihwaras. Kemudian, sumber data selanjutnya adalah berdasarkan observasi tentang implementasi pembelajaran matematika materi perkalian kelas $\mathrm{V}$ pada metode lattice. Adapun sumber data tersebut di pilih dengan teknik sempling snowball. Teknik sampling snowball adalah teknik pengambilan sampel yang ditentukan berdasarkan rekomendasi dari orang yang telah menjadi sampel sebelumnya. Kedua, data sekunder adalah data yang diperoleh secara tidak langsung dari objek peneliti. Sumber data sekunder meliputi dokumen, catatan atau laporan yang berkaitan dengan penelitian.

Teknik pengumpulan data pada penelitian ini adalah wawancara (interview), observasi, dan dokumentasi. Pertama, teknik wawancara. Teknik wawancara ini di gunakan untuk mencari data tentang implementasi pembelajaran matematika materi perkalian kelas V pada metode lattice. Selain itu, metode ini juga untuk mengetahui hambatan, serta upaya dalam mengatasi hambatan tersebut. Kedua, teknik observasi. teknik ini di gunakan sebagai teknik pendukung atau penguat dari adanya metode wawancara, sehingga teknik ini juga mencari data tentang implementasi pembelajaran matematika materi perkalian kelas $\mathrm{V}$ pada metode lattice, serta hambatan dan upaya dalam mengatasi hambatan tersebut yang sifatnya menguatkan dari data yang di dapatkan dari metode wawancara. Ketiga, teknik dokumentasi. Teknik ini di gunakan sebagai metode pendukung atau penguat dari adanya metode wawancara, serta memudahkan peneliti dalam mengumpulkan data baik dokumen tertulis atau gambar sebagai sumber data dalam penelitian ini sehingga data yang di peroleh lebih akurat.

Teknik analisa data yang digunakan dalam penelitian ini menggunakan langkahlangkah sebagai berikut: Pertama, pengumpulan data (Data Collection). Kedua, reduksi data (data reduction). Ketiga, display data. Ke-empat, Verifikasi dan penegasan kesimpulan (conclution drawing and verification). Kemudian, peneliti melakukan uji 
keabsahan data dengan uji Derajat Kepercayaan (credibility) dengan cara triangulasi. Adapun triangulasi yang digunakan adalah triangulasi teknik dan triangulasi sumber.

\section{HASIL DAN PEMBAHASAN}

Implementasi pembelajaran matematika materi perkalian kelas $\mathrm{V}$ pada metode lattice dilaksanakan melalui tiga tahapan. Tahapan tersebut adalah penanaman konsep dasar,

Pertama, penanaman konsep dasar. Pada tahap ini, guru mengenalkan konsep baru dalam kegiatan menghitung perkalian dengan menggunakan langkah-langkah metode lattice. Adapun langkah-langkah tersebut adalah sebagai berikut: 1) Guru menentukan bilangan yang akan di hitung. 2) Guru membuat kotak perkalian dan diberi garis diagonal sesuai dengan banyak bilangan yang dikalikan. 3)Guru mengalikan bilangan-bilangan yang berada di atas kotak dengan angka yang berada di samping kotak dengan berpatokan pada garis diagonal.4) Guru menaruh angka puluhan untuk kotak diagonal atas dan angka satuan pada diagonal bawah, jika hasil perkaliannya hanya satuan maka hasilnya ditambah nol. 5) Guru mengalikan semua angka lalu menempatkan hasilnya pada masing-masing kotak yang telah dibagi dua. 6) Selanjutnya guru menjumlahkan secara diagonal, dan untuk angka yang hasilnya dua digit, tambahkan digit puluhannya ke angka selanjutnya, dan bilangan yang berada dibawah kotak adalah hasil dari perkalian tersebut.

Kedua, pemahaman konsep. Tahapan ini bertujuan agar siswa lebih faham konsep matematika dengan cara memahami contoh soal yang di tuliskan oleh guru di papan tulis dengan metode pembelajaran yang sudah di jelaskan. Adapun contoh soal dan jawaban yang diberikan oleh bu isna (salah satu guru MI Glagahwangi) yaitu sebagai berikut:

Contoh soal perkalian : 354 x $35=\ldots . .$.

Membuat kotak perkalian/grid sesuai dengan banyak bilangan yang terlihat.

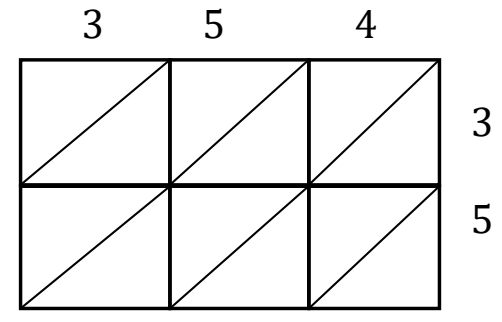

Perkalikan angka yang berada diatas grid dan disamping grid $3 \times 3=9$, puluhannya adalah 0 dan satuannya 9.

$3 \quad 5 \quad 4$

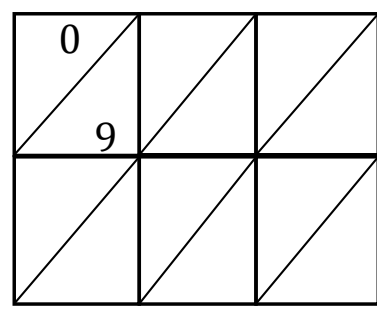


Selanjutnya, 5 × $2=10$, puluhannya adalah 1 dan satuannya 5 .

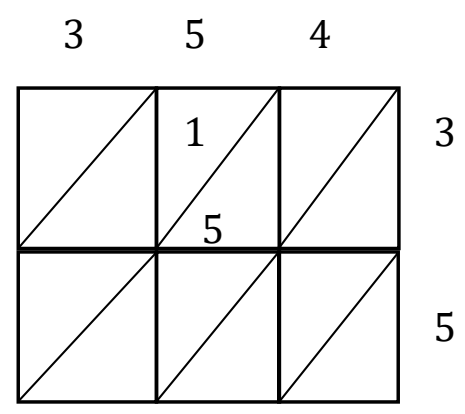

Dan seterusnya hingga didapatkan semua hasil dari 4x3, 5x3, 3x3, 4x5, 5x5, 3x5

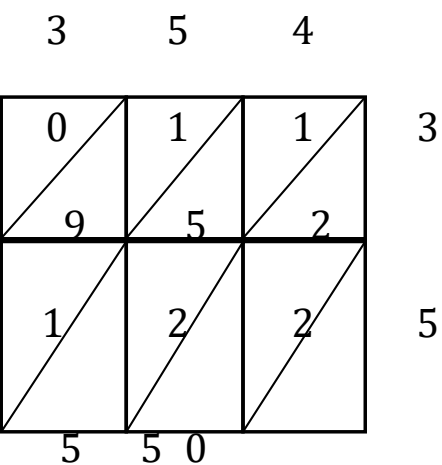

Kemudian selanjutnya jumlahkan secara diagonal, dan untuk angka yang hasilnya dua digit, tambahkan digit puluhannya ke angka selanjutnya, seperti berikut :

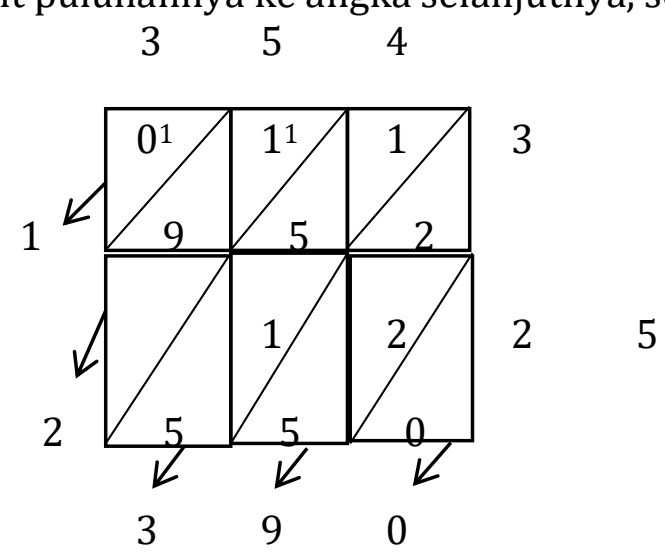

Jadi hasil dari $354 \times 35$ adalah 12.390 
Ketiga, pembinaan ketrampilan. Tahapan ini bertujuan untuk mengetahui tingkat pemahaman siswa dalam menggunakan metode lattice. Tahapan ini dilaksanakan dengan memberikan latihan soal kepada siswa di papan tulis, siswa mengerjakan dan menjawab soal bersama-sama didampingi oleh guru. Hal ini dilakukan agar siswa lebih terampil dalam mengerjakan soal perkalian dengan menggunakan metode lattice.

Adapun hambatan dalam proses pembelajaran serta upaya dalam mengatasi hambatan sebagai berikut:

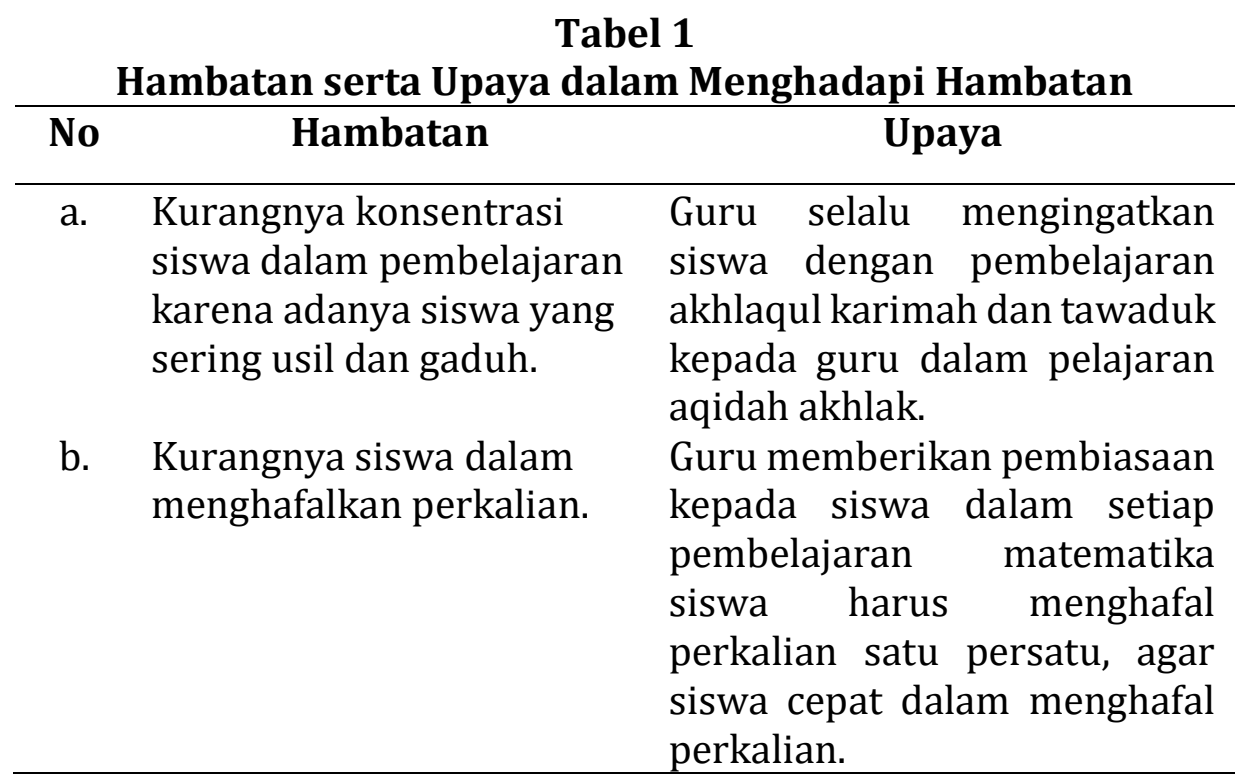

\section{KESIMPULAN DAN SARAN}

Implementasi pembelajaran matematika materi perkalian kelas V pada metode lattice di Madrasah Ibtidaiyah (MI) Ar-Rohmah Glagahwangi Sugihwaras Bojonegoro terdiri dari tiga tahapan sebagai berikut; a) penanaman konsep dasar yaitu pembelajaran suatu konsep baru matematika ketika siswa belum pernah mempelajari konsep tersebut. b) pemahaman konsep yaitu pembelajaran lanjutan dari penanaman konsep yang bertujuan agar siswa lebih memahami suatu konsep matematika. c) pembinaan keterampilan yaitu pembelajaran lanjutan dari penanaman konsep dan pemahaman konsep.

Hambatan dalam implementasi pembelajaran matematika materi perkalian kelas V pada metode lattice di Madrasah Ibtidaiyah (MI) Ar-Rohmah Glagahwangi Sugihwaras Bojonegoro adalah Kurangnya konsentrasi siswa dalam pembelajaran karena adanya siswa yang sering usil dan gaduh, Kurangnya siswa dalam menghafalkan perkalian.

Upaya mengatasi hambatan dalam implementasi pembelajaran matematika materi perkalian kelas V pada metode lattice di Madrasah Ibtidaiyah (MI) Ar-Rohmah Glagahwangi Sugihwaras Bojonegoro adalah selalu mengingatkan siswa dengan pembelajaran akhlaqul karimah dan tawaduk kepada guru dalam pelajaran aqidah akhlak, memberikan pembiasaan kepada siswa dalam setiap pembelajaran matematika siswa harus menghafal perkalian satu persatu, agar siswa cepat dalam menghafal perkalian.

Berdasarkan hasil penelitian, penulis memberikan saran sebagai berikut: 1) Bagi guru, selalu tingkatkan pengetahuan tentang metode pembelajaran, karena guru adalah kunci utama dalam proses belajar mengajar. 2) Bagi siswa, diharapkan agar lebih meningkatkan kesadaran pada dirinya masing-masing untuk dapat belajar dengan giat dan sungguh-sungguh. 3) Bagi 
calon guru, dapat menjadi suatu ilmu pengetahuan tersendiri yang bisa dijadikan masukan dan pedoman untuk bisa dipraktekkan pada situasi yang nyata

\section{REFERENSI}

Abdullah, Abdurrahman Saleh. (2016). Teori-teori Pendidikan Berdasarkan Al-Qur'an. Jakarta: PT. Rineka Cipta.

Arikunto, Suharsimi. (2013). Produser Penelitian Suatu Pendekatan Praktek. Jakarta: PT. Rienika Cipta

Djamarah, Syaiful Bahri. (2012). Prestasi belajar dan Kompetensi Guru. Surabaya: Usaha Nasional

Heruman. (2013). Model Pembelajaran Matematika di Sekolah Dasar. Bandung: Remaja Rosdakarya

Khumairoh, Intan. (2017). Pengaruh Penggunaan Metode Lattice Terhadap Hasil Belajar Peserta Didik Kelas V Sekolah Dasar. Skripsi: Universitas Islam Negeri Walisongo Semarang

Moleong, Lexy J. (2012). Metodelogi Penelitian Kualitatif. Bandung: Remaja Grafindo Persada

Moleong. (2017). Metode Penelitian Kualitatif. Bandung: PT Remaja Rosda Karya

Muchtar, A, Karim. dkk. (2015). Pendidikan Matematika I. Malang; Departemen Pendidikan dan Kebudayaan

Ramayulis. (2012). Ilmu Pendidikan Islam. Jakarta: Kalam Mulia

Rusman. (2011). Model-Model Pembelajaran Mengembangkan Profesionalisme Pendidik. Jakarta: Rajagrafindo

Sanjaya dan Wina. (2014). Strategi Pembelajaran Berorientasi Standar Proses Pendidikan. Jakarta: Kencana

Simanjuntak, Lisnawaty. (2015). Metode Pengajaran Matematika 1. Jakarta: PT.Rineka Cipta

Sobry Sutikno. (2013). Belajar dan Pembelajaran. Lombok: Holistica

Solikin, Nur Khulaifatur Rosidah, dkk. (2019). Penggunaan Metode Lattice Dalam Mengatasi Rendahnya Kemampuan Berhitung Operasi Perkalian. Prismatika: Jurnal Pendidikan dan Riset Matematika Vol. 2 No. 1 (2019).

Sugiyono. (2016). Metode Penelitian Kualitatif, Kuantitatif dan R\&D. Bandung: Alfabeta

Suprihatiningrum, Jamil. (2014). Strategi Pembelajaran. Jogjakarta: ArRuzz Media

Susanto, Ahmad. (2013). Teori Belajar dan Pembelajaran di Sekolah Dasar. Jakarta: Kencana

Suttrisno, Riyanto, Y., \& Subroto, W. T. (2020). Pengaruh Model Value Clarification Technique (Vct) Berbasis Kearifan Lokal Terhadap Motivasi Belajar Dan Hasil Belajar Siswa. NATURALISTIC : Jurnal Kajian Penelitian Pendidikan Dan Pembelajaran, 5(1), 718-729. Retrieved from https://journal.umtas.ac.id/index.php/naturalistic/article/view/836.

Wagiran. (2013). Metodologi Penelitian Pendidikan. Yogyakarta, Deepublish 
Yusuf, A. Muri. 2014. Metode Penelitian Kuantitatif, Kualitatif \& Penelitian Gabungan. Jakarta: PT Fajar Interpratama Mandiri.

Zubaidah. (2015). Peningkatan Hasil Belajar Matematika dengan Metode Lattice di Kelas III Sekolah Dasar Negeri Tahun Ajaran 2015. Skripsi: Universitas FKIP untan sengkawang. 